\title{
PROFIL DAYA TAHAN AEROBIK POSISI GUARD, FORWARD, DAN CENTER ATLET BOLA BASKET
}

\author{
Oleh: \\ Muhamad Fanani Augi Nugraha dan Cerika Rismayanthi \\ Jurusan Pendidikan Kesehatan dan Rekreasi FIK UNY
}

\begin{abstract}
Abstrak
Pemahaman atlet bola basket Kabupaten Indramayu tentang daya tahan aerobik masih terbatas. Tidak optimalnya daya tahan aerobik dapat mengakibatkan penurunan kemampuan konsentrasi, kecepatan reaksi dan mudah lelah. Penelitian ini bertujuan untuk mengetahui daya tahan aerobik posisi guard, forward, dan center atlet bola basket Kabupaten Indramayu.

Penelitian ini merupakan penelitian kuantitatif dengan desain penelitian deskriptif. Subyek penelitian ini adalah atlet bola basket Kabupaten Indramayu dengan jumlah 30 atlet. Pengambilan data menggunakan tes, dengan instrument yang digunakan adalah yo-yo intermittent recovery test. Teknik analisis data menggunakan analisis deskriptif yang dituangkan dalam bentuk persentase, yang terbagi dalam enam kategori pada norma $\mathrm{VO}_{2} \mathrm{Max}$.

Berdasarkan hasil penelitian menunjukan bahwa daya tahan aerobik $\left(\mathrm{VO}_{2} \mathrm{Max}\right)$ atlet bola basket Kabupaten Indramayu yang terdiri dari 30 atlet terdapat 25 atlet $(83,33 \%)$ dalam kategori sedang. Daya tahan aerobik $\left(\mathrm{VO}_{2} \mathrm{Max}\right)$ pada posisi guard $(80 \%)$ dalam kategori sedang, posisi forward $(81,81 \%)$ dalam kategori sedang, dan posisi center $(88,89 \%)$ dalam kategori sedang.
\end{abstract}

Kata kunci: Atlet bola basket Kabupaten Indramayu, Daya tahan aerobik, Yo-yo intermittent recovry test

Permainan bola basket diciptakan oleh seorang Amerika pada tahun 1891 yang bernama Dr. James A. Naismith. Permainan bola basket mempunyai tujuan memasukkan bola sebanyak mungkin ke basket (keranjang) lawan, serta menahan lawan agar jangan memasukkan bola ke basket (keranjang) sendiri dengan cara lempar tangkap, menggiring, dan menembak (Dedy Sumiyarsono, 2002:1). Bola basket dimainkan oleh dua tim yang masing-masing terdiri dari lima orang atlet. Terdapat berbagai posisi pemain diantaranya ada posisi guard, pada posisi guard terdiri dari point guard dan shooting guard. Posisi forward, terdiri dari small forward dan power forward dan posisi center. Pemain tengah (center) biasanya ditempati oleh pemain yang bertubuh paling tinggi dalam tim. Pada saat menyerang, center bertugas menerima bola dan menembakannya ke ring, sedangkan pada saat bertahan, pemain ini menjadi pertahanan terakhir. Power forward juga biasanya ditempati oleh pemain yang bertubuh tinggi karena bertugas sebagai penangkap bola pantul yang gagal masuk ke dalam ring (rebound), terutama saat bertahan. Dalam posisi menyerang seorang power forward diharapkan menangkap bola rebound dan segera menembakannya kembali ke dalam ring. Small forward umumnya diisi 
oleh pemain yang agresif dalam melakukan serangan ke daerah musuh dan juga memiliki tembakan yang konsisten dari bagian luar garis tembakan bebas. Shooting guard umumnya diisi oleh pemain dengan kemampuan bertahan dan mencuri bola yang baik. Dalam posisi menyerang shooting guard berperan sebagai pemegang bola kedua dan juga menembakan lemparan tiga angka. Point guard adalah pemain penyerangan yang biasanya memiliki umpan (passing) dan dribble.

Hasil dari tes kebugaran jasmani dapat dijadikan sebagai acuan dalam mengevaluasi kekuatan dan kelemahan yang dimiliki oleh atlet, sehingga para pelaku olahraga khususnya pelatih disemua tingkatan pembinaan baik di klub, Universitas atau di sekolah dapat meningkatkan performa permainan atlet dan membuat program latihan yang paling tepat dalam mencapai prestasi. Salah satu komponen kebugaran jasmani yang dapat diukur melalui tes kebugaran jasmani adalah daya tahan paru jantung yang biasa disebut juga dengan $\mathrm{VO}_{2}$ Max.

Daya tahan yang baik yang dimiliki seorang atlet akan mempengarui perkembangan keterampilan atlet itu sendiri, karena akan membantu seorang atlet dalam latihan dan pertandingan. Misalnya, dengan daya tahan yang baik maka seorang atlet akan mampu berlatih dalam waktu yang lebih lama dibandingkan atlet dengan kebugaran jasmani yang rendah. Dengan tingkat daya tahan yang baik dapat mengurangi kelelahan yang timbul, sehingga seorang atlet mampu berpikir dengan daya pikir yang tinggi, pola pikir yang kreatif dan konsentrasi yang tinggi. Sehingga dalam mengeluarkan kemampuan teknik, taktik dan strategi yang dimiliki dapat berjalan dengan baik dan optimal.

Para pelaku olahraga khususnya pelatih belum banyak yang menggunakan yo-yo intermittent recovery test sebagai cara mengukur daya tahan paru jantung atau $\mathrm{VO}_{2} \mathrm{Max}$ atlet, terutama pada atlet bola basket Kabupaten Indramayu yang masih belum mengetahui bentuk dan cara melakukan tesnya. Sehingga pengetahuan pelatih tentang yo-yo intermittent recovery test masih terbatas. Yo-yo intermittent recovery test merupakan perkembangan dari multistage fitnest test. Yo-yo intermittent recovery test memiliki kesamaan dengan multistage fitnest test dari tata pelaksanaannya yang mengharuskan peserta tes berlari di lintasan sepanjang 20 m dengan mengikuti aba-aba dari CD audio, perbedaan yang mencolok terletak pada jeda istirahat dan percepatan. Yo-yo intermittent recovery test mengharuskan peserta untuk berlari lalu beristirahat aktif selama 10 detik, sedangkan pada multistage fitnest test peserta berlari tanpa jeda istirahat dengan percepatan yang bertambah dengan perlahan pada setiap levelnya. Yo-yo intermittent recovery test digunakan oleh pelaku olahraga sebagai alat 
ukur $\mathrm{VO}_{2}$ Max khususnya pada cabang olahraga permainan yang cepat dan explosive secara intermittend.

Tipe latihan yang digunakan oleh atlet basket menggunakan kecepatan yang explosive dalam berlari lalu beristirahat aktif sambil dribbling, passing, shooting ataupun berfikir untuk membuat strategi, oleh sebab itu yo-yo intermittent recovery test sangat valid dilakukan pada cabang olahraga bola basket. Kebugaran aerobik membuat tingkat efisiensi yang tinggi pada sistem sirkulasi dan respirasi dalam membawa oksigen ke otot yang sedang bekerja.

Olahraga bola basket banyak menggunakan sistem anaerobik, tetapi sistem aerobik tidak dapat dipandang sebelah mata, sistem aerobik merupakan fondasi untuk meningkatkan system anaerobik. Karena pentingnya kebugaran aerobik maka setiap atlet harus mempunyai tingkat $\mathrm{VO}_{2}$ Max yang tinggi, dengan demikian kemampuan untuk menghirup oksigen secara maksimal pada saat latihan menjadi penting. Oleh karena itu, dibutuhkan persiapan yang matang. Salah satunya adalah kesiapan dari atlet itu sendiri, tentunya atlet dituntut untuk memiliki kapasitas daya tahan aerobik dan anaerobik yang baik. Untuk itu, perlu dilakukan penelitian tentang Profil Daya Tahan Aerobik antara Posisi Guard, Forward, dan Center Atlet Bola Basket Kabupaten Indramayu menggunakan Yo-yo intermittent recovery test.

\section{KAJIAN PUSTAKA}

\section{Bola Basket}

Bola basket adalah salah satu bentuk olahraga yang masuk dalam cabang permainan beregu. Permainan bola basket ini dimainkan oleh 2 tim, dengan tujuan memasukkan bola ke dalam keranjang lawan sebanyak mungkin, serta menahan serangan lawan agar tidak memasukkan bola ke dalam keranjangnya (Dedy Sumiyarsono, 2002: 1). Lebih lanjut Dedy Sumiyarsono (2002: 1) menyatakan bahwa dasar bermain bola basket dengan cara lempar tangkap, menggiring dan menembak dengan luas lapangan $28 \mathrm{~m} \mathrm{x} 15 \mathrm{~m}$ dapat terbuat dari tanah, lantai, dan papan yang dikeraskan. Permainan bola basket mempunyai tujuan dari kedua tim, yaitu mendapatkan angka dengan memasukkan bola ke dalam keranjang lawan dan mencegah lawan mendapatkan angka, permainan diawasi oleh officials (wasit), table officials, dan seorang commissioner (pengawas pertandingan) (Perbasi, 2006: pasal 1, 1). Dalam mencapai kemenangan, satu regu bola basket harus mengumpulkan angka sebanyakbanyaknya dengan cara memasukkan bola ke keranjang lawan dan mencegah lawan untuk melakukan hal yang serupa. Posisi pemain dalam permainan bola basket 
1. Guard

Posisi ini lebih sering berada di luar key hole atau perimeter area. Kebanyakan tim menempatkan pemain yang paling kecil dan paling cepat untuk posisi ini. Guard lebih sedikit beradu kontak fisik dengan pemain lawan dibandingkan dengan posisi forward dan center. Posisi guard sendiri terdiri dari dua macam; point guard dan shooting guard.

2. Forward

Posisi ini adalah seorang pemain yang bertugas melihat posisi kosong di dekat key hole untuk melakukan penetrasi ke dalam dan menerima passing kemudian melakukan drive ke dalam. Seorang forward biasanya bertubuh tinggi dan kuat. Tugas utamanya adalah melakukan rebound dan bekerja keras di point area. Pemain yang berada di posisi ini harus memiliki kemampuan menembak level medium. Posisi forward terdiri dari dua macam: small forward dan power forward.

3. Center

Center atau yang sering disebut Big Man adalah pemain yang posturnya paling tinggi dan besar di dalam timnya. Tugas utamanya adalah melakukan rebound dan bermain di area key hole. Seorang center harus dapat memperjuangkan rebound dan bermain di bawah ring. Sedangkan pada saat bertahan, pemain ini menjadi pertahanan terakhir.

\section{Kebugaran Jasmani}

Dalam bukunya Kebugaran Jasmani, Suharjana (2013: 3) mengatakan, "Kebugaran jasmani dapat diartikan sebagai kesanggupan seseorang untuk menjalankan hidup sehari-hari tanpa menimbulkan kelelahan yang berlebihan dan masih memiliki kemampuan untuk mengisi pekerjaan ringan lainnya." Setiap manusia memiliki waktu selama 24 jam sehari, namun tidak semua orang dapat melakukan banyak hal dalam waktu 24 jam tersebut.

Orang-orang yang memiliki kebugaran jasmani yang baik tentunya dapat melakukan banyak hal yang tidak mengakibatkan kelelahan yang berlebihan. Sama halnya pada dunia olahraga khususnya bagi atlet, setiap atlet tentu memiliki kebugaran jasmani yang berbedabeda yang memberikan dampak terhadap performa atlet tersebut. Menurut Djoko Pekik Irianto (2004: 10), kebugaran jasmani atau kebugaran fisik (physical fitness), yakni kemampuan seseorang melakukan kerja sehari-hari secara efisien tanpa timbul kelelahan yang berlebihan sehingga dapat menikmati waktu luangnya. Banyak sekali atlet yang menjalani sesi latihan yang berat sehingga mengalami proses pemulihan yang lambat. Namun bagi atlet yang memiliki kebugaran jasmani yang tinggi, proses pemulihan tersebut akan berjalan dengan cepat sehingga atlet dapat menikmati waktu senggang yang dimiliki. 


\section{Hakikat Daya Tahan Aerobik Pemain Bola Basket}

Daya tahan aerobik adalah kesanggupan jantung dan paru serta pembuluh darah untuk berfungsi secara optimal pada keadaan istirahat dan latihan untuk mengambil oksigen dan mendistribusikannya ke jaringan yang aktif untuk digunakan pada proses metabolisme tubuh (http://ib.fkuii.org/index). Daya tahan aerobik berarti "dengan oksigen" dan daya tahan aerobik berarti kerja otot dan gerakan otot yang dilakukan menggunakan oksigen guna melepaskan energi dari bahan-bahan otot. Kualitas latihan yang paling penting adalah takaran latihan atau dosis latihan yang dijabarkan dalam konsep FITT (Frekuensi, Intensity, Time, Type). Dalam melakukan latihan 3-5 kali seminggu dengan waktu latihan 20-60 menit setiap kali latihan. Intensitas menunjukan kualitas berat ringannya suatu latihan. Apabila dilakukan secara teratur dapat meningkatkan kapasitas daya tahan kardiorespirasi.

Dari berbagai uraian diatas, dapat diambil kesimpulan bahwa kapasitas aerobik atau daya tahan jantung paru merupakan salah satu komponen penting dalam kesegaran jasmani yang mana kapasitas kesegaran aerobik merupakan kemampuan jantung, paru-paru, dan pembuluh darah dalam menggunakan oksigen yang kemudian memanfaatkannya untuk dijadikan energi yang dapat digunakan untuk melakukan aktifitas sehari-hari dalam jangka waktu yang lama. Dalam setiap cabang olahraga latihan fisik yang pertama kali dilakukan adalah membentuk daya tahan umum, yang dilakukan dengan latihan aerobik. Aerobik adalah bentuk aktivitas yang membutuhkan oksigen. Sukadiyanto (2005:65) menyatakan fondasi aerobik adalah kemampuan peralatan organ tubuh olahragawan dalam menghirup, mengangkut, dan menggunakan oksigen yang diperlukan selama aktivitas berlangsung.

Peraturan PERBASI (2010: 12) menerangkan, pertandingan akan terdiri dari empat (4) periode dengan masing-masing periode sepuluh (10) menit, instensitas yang digunakan pada permainan ini cukup tinggi, dikarenakan permainan ini harus melakukan teknik dasar passing, dribbling, jumping, dan shooting dalam waktu yang singkat agar bola tidak dapat dikuasai oleh tim lawan. Biasanya setelah memasuki periode ke 3 dan ke 4 pemain akan mengalami penurunan performa yang disebabkan oleh buruknnya daya tahan aerobik setiap pemain. Pemain dengan daya tahan aerobik yang buruk dapat menyebabkan pemain mudah lelah, penurunan konsentrasi dalam berlatih maupun saat pertandingan, dan mudah terkena cidera. Pentingnya setiap pemain memiliki daya tahan aerobik yang baik adalah agar setiap pemain tidak mudah lelah, selalu fokus dalam latihan maupun pertandingan sehingga pelatih lebih mudah memberikan pengarahan, dan yang terutama agar pemain terhindar dari terkena 
cidera. Sehingga pemain yang memiliki tingkat daya tahan aerobik yang baik sangatlah penting.

\section{Tes Daya Tahan Paru Jantung}

Tes kebugaran jasmani merupakan suatu instrumen atau alat yang digunakan untuk mengukur kemampuan seseorang yang berkaitan dengan komponen-komponen kebugaran jasmani. Menurut Andi Suntoda (2009: 1), tes adalah suatu alat ukur atau instrument yang digunakan untuk memperoleh informasi/data tentang seseorang atau obyek tertentu. Data yang diperoleh merupakan atribut atau sifat-sifat yang melekat pada individu atau objek yang bersangkutan. Data yang terhimpun meliputi ranah kognitif, afektif, dan motorik. Data yang bersifat kognitif dijaring melalui tes tulis (essay, obyektif) dan lisan; data bersifat afektif dapat dihimpun melalui tes bentuk skala sikap, angket, dan observasi secara langsung terhadap obyek yang akan diukur; data yang bersifat motorik dapat dihimpun misalnya melalui tes kemampuan dan gerak dasar, fungsional, dan tes keterampilan cabang olahraga.

Tes kebugaran jasmani bagi atlet berbeda-beda sesuai dengan kebutuhan fisik cabang olahraga yang bersangkutan. Peserta tes harus dipastikan terlebih dahulu dalam keadaan sehat dan tidak sedang dalam kondisi kelelahan. Tes kebugaran kardiorespirasi yang dapat dilakukan salah satunya adalah Yo-yo intermittent recovery test. Yo-yo intermittent recovery test merupakan variasi dari multistage fitness test. Tes ini menuntut peserta tes untuk berlari sesuai perintah cd audio di lintasan sepanjang 20 meter dan peserta diharuskan kembali ke garis start setelah mendengar perintah lanjutan dari cd audio. Menurut Castagna et. al. (2006: 320), kecepatan dimulai dari $10 \mathrm{~km} / \mathrm{h}$ dan setelah stage 3 kecepatan akan bertambah $0.5 \mathrm{~km} / \mathrm{h}$ per stage, peserta tes akan diberhentikan jika peserta tidak dapat mengikuti aba-aba dari audio dan memiliki istirahat aktif selama 10 detik setiap melewati 2 shuttle.

Istirahat aktif pada yo-yo intermittend recovery test merupakan perbedaan yang paling dapat dilihat jika dibandingkan dengan multistage fitness test yang tidak memiliki jeda istirahat aktif. Kecepatan pada masing-masing tes juga menjadikan perbedaan yang mencolok seperti pada yo-yo intermittent recovery test kecepatan dimulai dari $10 \mathrm{~km} / \mathrm{h}$ sedangkan multistage fitness test dimulai dari kecepatan $5 \mathrm{~km} / \mathrm{h}$. Tata Cara Pelaksanaan Test adalah sebagai berikut:

INTERMITTENT RECOVERY TEST

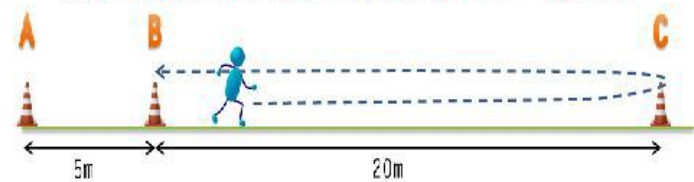

Gambar 1. Gambar Yo-Yo Intermittend Recovery Test 
A. Atlet berada pada kun penanda $5 \mathrm{~m}(\mathrm{~B})$

B. Atlet mulai berlari ke kun penanda 20m (C) sesuai dengan bunyi 'bip' dari audio Yo-yo intermittent recovery test

C. Setelah mencapai kun penanda (C) dan mendengar 'bip', atlet berbalik dan kembali ke titik awal (B) sebelum 'bip' berikutnya.

D. Setelah mencapai (B), sampel melakukan 'istirahat aktif' selama 10 detik untuk berjalan atau jogging ke kun penanda (A) dan kembali ke penanda (B), kemudian siap lagi untuk melakukan balikan 2x20m berikutnya ketika mendengar suara 'bip' lagi.

E. Ketika atlet tidak dapat kembali ke kun penanda (B) dalam waktu yang dialokasikan mereka menerima peringatan.

F. Pada saat balikan berikutnya melakukan hal yang sama maka atlet tersebut diberhentikan dan dicatat pada balikan ke berapa sampel tersebut gagal.

Teknik pengumpulan data yang digunakan adalah dengan tes dan pengukuran. Metode penelitian yang digunakan adalah survai dengan alat yo-yo intermittent recovery test yakini tes ini mengharuskan atlet untuk berlari sejauh 20 meter dengan waktu yang diiringi dengan bunyi bip dari rekaman CD. Atlet harus menempatkan satu kaki atau di luar penanda 20 meter di akhir setiap shuttle. Yo-yo intermittent recovery test digunakan oleh pelaku olahraga sebagai alat ukur $\mathrm{VO}_{2}$ Max khususnya pada cabang olahraga permainan yang cepat dan explosive secara intermittend. Tipe latihan yang digunakan oleh atlet basket menggunakan kecepatan yang explosive dalam berlari lalu beristirahat aktif sambil dribbling, passing, shooting ataupun berfikir untuk membuat strategi, oleh sebab itu yo-yo intermittent recovery test sangat valid dilakukan pada cabang olahraga bola basket (Castagna, C., dkk, 2008).

\section{METODE PENELITIAN}

Penelitian ini merupakan penelitian deskriptif kuantitatif. Metode yang digunakan dalam penelitian ini adalah metode survey dengan menggunakan teknik pengumpulan data berupa tes dan pengukuran. Populasi penelitian ini adalah seluruh atlet bola basket Kabupaten Indramayu putra dan putri yang berjumlah 30 orang. Tehnik sampling yang digunakan dalam penelitian ini adalah total sampling karena seluruh populasi dijadikan sebagai sampel penelitian. Penelitian ini menggunakan populasi atlet bola basket putra dan putri Kabupaten Indramayu berjumlah 30 orang yang terdiri dari 17 orang atlet putra dan 13 orang atlet putri. Instrumen yang digunakan untuk mengukur daya tahan aerobik yaitu yo-yo intermittent recovery test yakni tes ini mengharuskan atlet untuk berlari sejauh 20 meter dan peserta 
diharuskan kembali kegaris start setelah mendengar perintah lanjutan dengan waktu yang diiringi bunyi bip dari rekaman CD.

\section{HASIL PENELITIAN}

Data penelitian di peroleh dari tes daya tahan paru jantung atau daya tahan aerobik dengan menggunakan metode yo-yo intermittent recovery test, data yang diperoleh adalah total jarak yang di tempuh peserta yang dikalkulasi menggunakan rumus dari Bangsbo, dkk. (2008). Data $\mathrm{VO}_{2}$ Max dari yo-yo intermittent recovery test kemudian dikategorikan menggunakan tabel $\mathrm{VO}_{2}$ Max dari Haywood (1998). Berdasarkan penelitian yang dilakukan, didapatkan data sebagai berikut:

\section{A. Posisi Guard}

1. Tingkat Daya Tahan Aerobik $\left(\mathrm{VO}_{2} \mathrm{Max}\right)$ Atlet Bola Basket Kabupaten Indramayu Posisi Guard Putra

Data menunjukkan dari atlet putra dengan posisi guard yang mengikuti tes daya tahan paru jantung metode yo-yo intermittent recovery test berjumlah enam atlet yang terdiri dari beberapa kategori yaitu kategori sedang berjumlah empat atlet (66,6 \%), dan kategori baik berjumlah dua atlet $(33,3 \%)$.

2. Tingkat Daya Tahan Aerobik $\left(\mathrm{VO}_{2} \mathrm{Max}\right)$ Atlet Bola Basket Kabupaten Indramayu Posisi Guard Putri

Data di bawah ini menunjukkan dari atlet putri dengan posisi guard yang mengikuti tes daya tahan paru jantung metode yo-yo intermittent recovery test berjumlah empat atlet dan empat atlet tersebut masuk kedalam kategori yang sama yaitu sedang $(100 \%)$.

B. Posisi Forward

1. Tingkat Daya Tahan Aerobik Atlet Putra Bola Basket Kabupaten Indramayu Posisi Forward

Data menunjukkan dari atlet putra dengan posisi forward yang mengikuti tes daya tahan paru jantung metode yo-yo intermittent recovery test berjumlah enam atlet yang terdiri dari beberapa kategori yaitu kategori sedang berjumlah empat atlet $(66,6$ $\%)$, dan kategori baik berjumlah dua atlet $(33,3 \%)$.

2. Tingkat Daya Tahan Aerobik Atlet Putri Bola Basket Kabupaten Indramayu Posisi Forward

Data menunjukkan dari atlet putri dengan posisi forward yang mengikuti tes daya tahan paru jantung metode yo-yo intermittend recovery test berjumlah lima atlet dan lima atlet tersebut masuk kedalam kategori yang sama yaitu sedang (100\%). 


\section{Posisi Center}

1. Tingkat Daya Tahan Aerobik Atlet Putra Bola Basket Kabupaten Indramayu Posisi Center

Data menunjukkan dari atlet putra dengan posisi center yang mengikuti tes daya tahan paru jantung metode yo-yo intermittent recovery test berjumlah lima atlet yang terdiri dari beberapa kategori yaitu kategori sedang berjumlah empat atlet (80\%), dan kategori baik berjumlah satu atlet $(20 \%)$.

2. Tingkat Daya Tahan Aerobik Atlet Putri Bola Basket Kabupaten Indramayu Posisi Center

Data menunjukkan dari atlet putri dengan posisi center yang mengikuti tes daya tahan paru jantung metode yo-yo intermittent recovery test berjumlah empat atlet dan empat atlet tersebut masuk kedalam kategori yang sama yaitu sedang (100 \%).

\section{PEMBAHASAN}

Berdasarkan hasil perhitungan dan analisis data penelitian menunjukan bahwa tingkat daya tahan aerobik $\left(\mathrm{VO}_{2} \mathrm{Max}\right)$ atlet bola basket Kabupaten Indramayu dalam kategori sedang. Sebanyak 25 atlet $(83,33 \%)$ dari keseluruhan responden yang berjumlah 30 orang, terdiri dari 17 atlet putra dan 13 atlet putri. Lebih rinci hasil perhitungan dan analisis data penelitian menujukan bahwa rata-rata tingkat daya tahan aerobik $\left(\mathrm{VO}_{2} \mathrm{Max}\right)$ atlet putra Kabupaten Indramayu dalam kategori sedang. Yaitu pada 12 atlet (70,58 \%) dari 17 atlet. Dan berdasarkan hasil perhitungan dan analisis data penelitian menunjukan bahwa keseluruhan tingkat daya tahan aerobik $\left(\mathrm{VO}_{2} \mathrm{Max}\right)$ atlet putri Kabupaten Indramayu dalam kondisi sedang yaitu 13 atlet (100\%) dari 13 atlet.

$\mathrm{VO}_{2} \mathrm{Max}$ atlet bola basket Kabupaten Indramayu masih dalam kategori sedang. Hal ini menunjukan bahwa kondisi kebugaran jasmani, khususnya daya tahan kardiovaskular yang dimiliki atlet bola basket Kabupaten Indramayu masih belum optimal, kondisi tersebut disebabkan oleh beberapa faktor, menurut Nagle,F.J dalam Junusul Hairy (1989: 191) faktorfaktor yang perlu dipertimbangkan dalam menentukan konsumsi oksigen maksimal adalah data tes-tes khusus mengenai postur tubuh, massa otot yang digunakan dalam latian, durasi latian, efisiensi mekanis dan motivasi.

Berdasarkan hasil penelitian posisi guard, forward, dan center atlet bola basket Kabupaten Indramayu dalam kategori sedang, itu disebabkan semua posisi mendapatkan porsi latihan daya tahan kardiovaskular yang sama, seharusnya posisi guard dan forward 
yang memiliki ukuran badan yang relatif lebih kecil dan membutuhkan mobilitas yang tinggi mendapatkan porsi latihan daya tahan kardiovaskular yang lebih misalnya intensitas dan durasinya yang lebih lama di bandingkan posisi center yang memiliki badan besar dan jarang untuk bergerak. Dengan latihan yang rutin selama minimal tiga kali dalam seminggu, maka daya tahan kardiovaskular atlet akan cepat meningkat dan semakin baik. Frekuensi latihan atlet bola basket Kabupaten Indramayu hanya dilakukan seminggu dua kali, dan lebih menekankan pada latihan teknik, taktik, dan strategi, sementara faktor daya tahan kardiovaskular kurang diperhatikan, sehingga hal ini sangatlah tidak mendukung untuk meningkatkan daya tahan kardiovaskular.

Daya tahan kardiovaskular dapat meningkat apabila banyak melakukan latihan-latihan dalam bentuk aerobik secara continue, seperti jogging, Berdasarkan hasil penelitian yang sudah dilakukan maka dapat diambil kesimpulan bahwa tingkat daya tahan aerobik $\left(\mathrm{VO}_{2}\right.$ Max) atlet bola basket Kabupaten Indramayu pada posisi guard, forward, dan center dalam kategori sedang. Agar meningkatkan prestasi bola basket Kabupaten Indramayu perlu ditambahkan beberapa upaya seperti menambah jam latihan, membagi porsi latihan antara teknik, taktik, dan latihan kardiovaskular dapat tertata dengan baik, selain itu bisa juga dilakukan dengan cara-cara lain dimana dari situ tujuan utamanya adalah agar mampu meningkatkan daya tahan kardiovaskular atlet bola basket Kabupaten Indramyu sehingga harapanya prestasi bola basket Kabupaten Indramayu menjadi lebih baik. Selain sebagai upaya peningkatan prestasi, daya tahan juga penting bagi atlet akan mempermudah dalam menghadapi beban kerja lainnya. Dengan nilai $\mathrm{VO}_{2}$ Max yang tinggi dapat meningkatkan untuk kerja pada aktivitas daya tahan, yaitu meningkatkan kemampuan rata-rata kerja lebih besar atau lebih cepat.

\section{KESIMPULAN}

Berdasarkan hasil penelitian menunjukan bahwa daya tahan aerobik $\left(\mathrm{VO}_{2} \mathrm{Max}\right)$ atlet bola basket Kabupaten Indramayu yang terdiri dari 30 atlet terdapat 25 atlet $(83,33 \%)$ dalam kategori sedang. Daya tahan aerobik $\left(\mathrm{VO}_{2}\right.$ Max) pada posisi guard $(80 \%)$ dalam kategori sedang, posisi forward $(81,81 \%)$ dalam kategori sedang, dan posisi center $(88,89 \%)$ dalam kategori sedang.

\section{DAFTAR PUSTAKA}

Ahmadi, Nuril. (2007). Permainan Bola Basket. Solo: Era Intermedia.

Andi Suntoda Situmorang. (2009). Tes, Pengukuran, dan Evaluasi Cabang Olahraga.http://file.upi.edu/Direktori/FPOK/JUR.PEND.OLAHRAGA/19580620198 66011-ANDI_SUNTODA_SITUMORANG/Pntrn_Softball.pdf 
Bangsbo, J., Iaia, F. M., \& Krustrup, P. (2008). The Yo-Yo Intermittent Recovery Test: A Useful Tool for Evaluation of Physical Performance in Intermittent Sports. Journal Sport Medicine 38 (1): 37-51.

Brittenham, G. (1998). Petunjuk Lengkap Latihan Pemantapan Bolabasket (Bagus Pribadi. Terjemahan). Jakarta: PT Raja Grafindo Persada.

Castagna, C., Impellizzeri, F. M., Rampinini, E., D’Ottavio, S., \& Manzi, V. (2008). The YoYo Intermittent Recovery Test In Basketball Players. Journal of Science and Medicine In Sport 11: 202-208.

Danny Kosasih. (2008). Fundamental Basketball. Jakarta: Karmedia.

Dedy Sumiyarsono (2002). Keterampilan Bola Basket. Yogyakarta: Fakultas Ilmu Keolahragaan (FIK) Universitas Negeri Yogyakarta UNY.

Djoko Pekik Irianto. (2004). Dasar-dasar Latihan Kebugaran. Yogyakarta: FIK UNY.

Junusul Hairy. (1989). Fisiologi dan Olahraga. Jakarta: Depdikbud.

Loly Zulfiyani. (2015). Persepsi Atlet Terhadap Tingkat Kelelahan Pada Multisatge Fitness Test Dan Yo-Yo Intermittend Recovery Test Di Tim Basket Putra SMA Negeri 4 Yogyakarta. Skripsi. Yogyakarta: FIK UNY.

Oliver. (2007). Dasar-dasar Bola Basket. Bandung: Pakar Raya Ahmadi.

PERBASI. (2010). Peraturan Resmi Bola Basket 2010. Diakses dari http://brosoppemalang.blogspot.com/2012/06/fiba-peraturan-resmi-bola-basket.html, pada tanggal 10 Mei 2017, pukul 20.00 WIB. Menurut Dal Monte yang dikutip dari Bompa (1994: 27).

Rusli Lutan. (2002). Menuju Sehat Bugar. Jakarta : Depdikbud

Sharkey, Brian J. (2003). Kebugaran dan Kesehatan. Jakarta: PT Raja Gravindo Persada. Alfabeta.

Suharjana. (2013). Kebugaran Jasmani. Yogyakarta: Jogja Global Media.

Sukadiyanto. (1997). Pembinaan Kondisi Fisik Petenis. Yogyakarta: Fakultas Ilmu Keloahragaan UNY.

Sukadiyanto. (2005). Pengantar Teori Metodologi Melatih Fisik. Yogyakarta. Fakultas ilmu Keloahragaan. Universitas Negeri Yogyakarta. 